\title{
GAY, ROXANE. AYITI. NEW YORK: GROVE ATLANTIC, 2018. ${ }^{1}$
}

\author{
Priscilla Pellegrino de Oliveira
}

Doutoranda em Literaturas de Língua Inglesa pela UERJ.

10 presente trabalho foi realizado com apoio da Coordenação de Aperfeiçoamento de Pessoal de Nível Superior - Brasil (CAPES) - Código de Financiamento 001.

Via Atlântica, Sâo Paulo, n. 38, pp. 401-412, dez. 2020. doi: 10.11606/va.i38.157496 
Roxane Gay é uma reputada ensaísta, escritora e professora universitária americana, colunista do New York Times, descendente de haitianos, que escreve ficção e não ficção sobre feminismo e diáspora haitiana nos Estados Unidos. Entre suas obras de ensaios estão os best-sellers Bad Feminist (Má Feminista) (2014) e Hunger (Fome) (2017) e seu único romance, An Untamed State (2014) (ainda sem tradução para o português), está passando por uma adaptação para o cinema.

Ayiti (2011), um livro de contos, republicado em 2018, com duas novas histórias, foi a primeira obra de ficção de Roxane Gay, apesar de conter elementos biográficos e históricos. Quinze contos exploram a cultura haitiana através de um realismo cheio de conflitos sobre pessoas tendo que assimilar uma outra cultura, a americana, ou conviver com as contradições em um país como o Haiti. Assuntos recorrentes são: abuso, identidade, migração Haiti-Estados Unidos, violência e racismo. Os contos não seguem um formato único e alguns dos textos apresentam um estilo misto de prosa e ensaio, parecendo lembranças poéticas.

Ayiti explora experiências de haitianos tanto no Haiti quanto nos Estados Unidos, na condição de imigrantes, através de narrativas que retratam um Haiti não visto na mídia, a qual mostra um país destruído por desastres, guerras e pela pobreza. Um dos contos lembra que o Haiti, historicamente, foi a primeira nação negra livre, não delineando, obviamente, uma vi- 
são otimista do país, apesar de diversos personagens expressarem a saudade da pátria e a conexão com a cultura do país.

É um livro sobre diáspora, mostrando a ambivalência e os estigmas sociais do povo haitiano, assim como as contradições presentes na nação: por um lado, a riqueza cultural e, por outro, a extrema pobreza. Seus personagens refletem estereótipos através do imaginário de quem está de fora assim como a dura realidade de quem está dentro, em uma relação de amor e ódio.

Os contos que se passam no Haiti retratam a cultura e os costumes do país, assim como a dura realidade enfrentada pelos haitianos devido à violência e à pobreza com as quais a população tem de conviver. Em "There is no E in zombi, which means there can be no you or we", a autora descreve, de acordo com a tradição vodu, como se transforma alguém em zumbi. Logo em seguida inicia-se o conto de uma jovem que amava um colega desde que estudaram juntos na escola. Ele, Lionel, se tornara um homem cobiçado por todas as mulheres de Porto Príncipe e cada noite escolhia uma dessas mulheres para passar a noite com ele. Micheline, então, na noite de seu aniversário, arrumou-se e foi a escolhida. Na manhã seguinte, é rejeitada e adoece. A família, católica, resolve então chamar um mambo para tentar curá-la. Decide então fazer um vodu para Lionel e transformá-lo em zumbi, o que consegue sem grande esforço, tornando-o seu 
prisioneiro morto-vivo. Nesse conto fantástico, o misticismo rouba a cena, mostrando o quanto é forte a cultura local no que diz respeito às suas raízes históricas e culturais. Já na história intitulada Voodoo child, que se passa nos Estados Unidos, amigas que dividem o apartamento são unidas pela amizade em uma relação também de medo por parte da americana que acredita que a amiga haitiana seja praticante de vodu. 0 conto em primeira pessoa do ponto de vista da garota haitiana nos revela que ela é católica e só ouvira falar em vodu em um filme americano estrelado por Bill Cosby. Mesmo assim, ela canta e dança com roupas extravagantes no apartamento, colocando agulhas em bonecas para que a amiga americana pense que ela realmente tem poderes sobrenaturais. Aqui fica clara a ironia da escritora que, de forma bem-humorada, demonstra o reducionismo estereotipado a que um povo como o haitiano é visto por um povo de fora como o norte-americano.

Em contos que se passam no Haiti, o tom é mais grave e realista como, por exemplo, em A cool, dry place, em que Gabi e o marido Yves planejam se mudar do Haiti, mas não têm dinheiro para comprar as passagens. Moram de favor na casa da mãe em Porto Príncipe e não têm sequer coragem de ter um filho. Então, Yves consegue arrumar dois lugares em um barco ilegal para Miami. Gabi começa a imaginar-se levando outra vida nos Estados Unidos, demonstrando uma visão idealizada do país para onde pretende 
ir: "I am dreaming of Miami and places where Yves and I are never hungry or tired or scared or any of the other things we have become" (GAY, 2018, p. 300). Em seguida faz um questionamento da realidade que vive no Haiti: "What an odd country Haiti is, with the internet, computers, fax machines, and photocopiers in offices and the people who use them living in shacks with the barest of amenities. We are a people living in two different times" (p. 301). Yves é formado em engenharia e acredita poder trabalhar nos Estados Unidos. Pensam em talvez morar em Little Haiti, se conseguirem sobreviver à viagem, o que pode não acontecer. 0 conto termina com o casal na embarcação para Miami, em meio ao oceano, fazendo amor como se fosse a última vez, pois seu destino é incerto.

Em Lacrimosa, também em Porto Príncipe, Marise decide alugar um quarto para um soldado brasileiro, que está em missão para a ONU. Eles se envolvem sexualmente e ele relata seus feitos no país, de que forma usa suas armas e seus gases lacrimogêneos para ferir e sufocar as pessoas. Ela então se dá conta de que uma hora ele terá de ir embora e ela ficará sozinha com seu filho pequeno. Um dia, acidentalmente, o menino pega os sprays lacrimogêneos e os mostra para a mãe. Assim, o conto termina no momento de maior tensão, com as lágrimas do filho em seus braços. "The harder they come" descreve, sob o ponto de vista de uma mulher haitiana, como é para os haitianos receberem turistas americanos em uma praia es- 
pecífica para o turismo no Haiti. A praia é parada para navios de cruzeiro e os americanos se divertem com as bebidas e a beleza da paisagem, como obseva-se a seguir: "They drink and drink and drink and get louder and happier. They ask us to take their pictures and they point their cameras at us so when they return home, they can have friends over for wine to show off all the dangerous places they have been" (p. 215). Porém, a narradora denuncia outra verdade: o turismo sexual que ocorre no local, na própria praia, por trás das plantas e nas pedras de forma furtiva e rápida.

Um dos contos mais longos da obra, "In the manner of water or light", narra a história de três mulheres de três gerações da mesma família. A história é contada sob o ponto de vista da neta, nascida nos Estados Unidos, para onde a mãe migrou aos 22 anos. A avó trabalhava em uma fazenda de cana-de-açúcar, na divisa com a República Dominicana, onde conheceu o marido. Era 1937 e os dois vivenciaram um fato histórico, um massacre ocorrido no Rio Dajabón, chamado de Rio do Massacre após o acontecimento: dominicanos mataram haitianos que viviam na fronteira e jogaram seus corpos no rio, que virou um rio de sangue. 0 massacre foi uma ordem do ditador Rafael Trujillo, como é descrito a seguir: "It was General Rafael Trujillo who ordered all the Haitians out of his country, who had his soldiers interrogate anyone whose skin was too dark, who looked like they belonged on the other side of the border" (p. 169). Ali, a mãe foi concebida e seu 
avô morto no mesmo dia. A avó sobreviveu ao massacre e conseguiu fugir. Nesse conto, as personagens são trabalhadas com mais profundidade psicológica e em diferentes perspectivas em relação ao que chamam de lar. Para a avó, é impossível deixar o país e sua história para trás; para a mãe, que sente cheiro de sangue 24 horas por dia, é impossível voltar para a sua terra natal; e para a neta, o Haiti não é seu ponto de partida. Sua realidade é outra, pois é americana e filha de uma haitiana e de um médico judeu de Tel Aviv. 0 único incômodo que sente é ser chamada de mulata pelos colegas americanos.

Há outros textos menores, mas não menos importantes, a serem mencionados. Em All things being relative, Gay faz um paralelo histórico entre os donos de minas de cobre no estado de Michigan, nos Estados Unidos, e os escravos que ali trabalharam. A tecnologia substitui a mão-de-obra, o recurso natural se acaba e o que sobra é abandono. 0 paralelo continua com a constatação de que há notícias ruins em Michigan hoje em dia - recessões, desempregos, etc.- e de que o Haiti:

is an island of contradictions. The sand is always warm. The water is so clear-blue bright that it is sometimes painful to behold. The art and music are rich, textured, revelatory, ecstatic. The sugarcane is raw and sweet. And yet. What most people think they know is this: Haiti is the poorest country in the Western Hemisphere. Her people eat mud cakes. (p. 226) 
Ou seja, mesmo um grave problema nos Estados Unidos não chega perto da severidade dos problemas do Haiti.

Em Gracia, Nacaragua y lo sentimos, de forma ensaística, em um misto de inglês e espanhol, a autora, revelando que a Nicarágua é agora considerada o país mais pobre do ocidente, também relata como é carregar esse título sob o ponto de vista haitiano. Em What you need to know about a haitian woman, fala ironicamente sobre a dureza de uma mulher haitiana que é capaz de matar uma galinha, deixando os pintinhos abandonados, somente para engordá-los e comê-los também.

A temática do sonho americano aparece de forma constante nos contos de Gay, como uma forma de retratar o dissabor do povo haitiano em relação à própria pátria, não só por conta das dificuldades econômicas e políticas, mas também por questões culturais. Em Ofghosts and shadows, duas jovens lésbicas haitianas sofrem preconceito por parte da sociedade e, por saberem como é a sociedade na qual estão inseridas, se encontram sempre em locais escondidos. Amélie e Marie Françoise estão juntas há muitos anos e foram surpreendidas uma vez pela mãe de Amélie, que fingiu não ter visto. 0 tempo todo ela relata o medo de demonstrar afeto em um local público, tendo que encontrar a amante em festas particulares voltadas para o público gay. Sonham em poder assumir o relacionamento e em viver em um país onde teriam liberdade: 
os Estados Unidos. "We are the women people ignore because two women loving each other is an American thing" (p. 262) e "on Saturday nights in the back room of someone's house in Port-au-prince. The rum is watered down. We have to pay tem dollars to get in, and the entire time, we try to pretend we are in New York or Miami or Montreal, at a club with friends" (p. 264).

Em The dirt we do not eat, ocorre o relato de correspondências entre primas. Uma foi para Miami e manda cartas com descrições da "cidade dos sonhos" para a outra prima que ficou no Haiti. Em uma dessas cartas, a prima de Miami pergunta se é verdade que os haitianos estão comendo lama como lera em um jornal. A prima do Haiti se surpreende com o fato de a prima de Miami pensar que isso seria possível e responde, rancorosa: "Some mornings we wake, our stomachs empty, our stomachs angry, but never do we look to the ground beneath our feet with longing in our mouths. We chew on our pride. The dirt we do not eat" (p. 241).

Nos contos em que haitianos são retratados nos Estados Unidos, existe uma relação de amor e ódio no que diz respeito aos dois países. Em Motherfuckers, Gerárd, um garoto de 14 anos, odeia os Estados Unidos, o fato de ter que viver lá, a língua que eles falam e especialmente o frio que faz. Mora em um apartamento pequeno com os pais, a irmã e um primo, todos tentando se acostumar com a "América". O pai era jornalista no Haiti, agora é cortador de carne em uma 
deli. Na escola, Gerárd é chamado de HBO. No início, acha o apelido bacana por pensar se tratar do canal de televisão. No entanto, seu ódio só aumenta quando ganha uma colônia de presente dos colegas de classe e descobre que, na verdade, HBO significa horrible body odor, demonstrando o preconceito contra sua nacionalidade.

About my father's accent não é exatamente uma narrativa, mas uma lembrança infantil, talvez autobiográfica, de como a narradora (autora?) e a irmã achavam engraçado o sotaque do pai falando inglês, mesmo após 30 anos morando nos Estados Unidos. Elas já haviam nascido lá e eram falantes nativas da língua inglesa, diferentemente dos pais, imigrantes. Diz que seu pai soa como Porto Príncipe.

Cheap, fast, filling conta a história de Lucien, um homem de migrou para os Estados Unidos ilegalmente deixando esposa e filhos no Haiti com promessa de mandar dinheiro para a família. Havia recebido o conselho de comer somente hot pockets porque eram baratos, rápidos de preparar e gostosos. Foi para Miami porque adorava a série Miami Vice. Mais uma vez, Miami é idealizada: "He loves the idea of Miami as a perfect place where problems are Always solved and there are beautiful women as far as a man can see" (p. 158). No entanto, sua realidade nos Estados Unidos não é muito perfeita. Liga para a família e finge ter uma vida melhor, fazendo promessas que não pode 
cumprir, mas na verdade mal consegue se alimentar, vivendo de bicos.

0 conto Sweet on the tongue, também longo e com aprofundamento psicológico de alguns personagens, conta a história de um casal bem sucedido nos Estados Unidos. Ela, médica, haitiana, narra seu encontro e casamento com um agente de atores americano de Hollywood. Therese e toda a família se mudara do Haiti para os Estados Unidos, exceto o pai, que preferiu permanecer em seu país de origem. 0 conto se inicia com uma visita à avó e a personagem vai narrando sua história em breves flashbacks desde o encontro com o marido até o momento. Mesmo com toda a família morando nos Estados Unidos, decidem se casar e passar a lua de mel no Haiti, em um resort. Durante esse período, é sequestrada por 3 dias até que a família paga o resgate e ela é solta. Havia sido levada para um armazém de cana-de-açúcar, violentada e espancada pelos sequestradores. Após 4 meses e vários tratamentos médicos, descobre uma gravidez. Fica a dúvida da paternidade, mas o final é feliz com o nascimento do filho e o restabelecimento de sua vida conjugal. No entanto, o Haiti continua sendo visto como um lugar onde as condições para se viver são insustentáveis, como relata a personagem principal: "Home is an island in the caribbean. Some call it a jewel. Everyone who leaves the place calls it home though few of us actually want to be there, not the way it is now" (p. 148). 
Assim, Ayiti é uma bela obra sobre deslocamentos no espaço e sobre o imaginário Haiti-Estados Unidos, que retrata a vida dos haitianos sob diferentes pontos de vista e em diferentes lugares. 0 sonho da imigração e da possibilidade de levar uma vida melhor, menos sofrida, é uma constante, estando presente em quase todos os textos. Porém, a relação com a terra natal é ambígua: uma mistura de repulsa e atração.

\section{Referências}

GAY, Roxane. Ayiti. New York: Grove Atlantic, 2018. 